related to respiratory infections in infancy and to atopy. Incident wheeze from one to 7 years was strongly associated with atopy, while late-onset wheeze was related to rhino conjunctivitis, smoking and (marginally) body mass.

Conclusions Advances in the understanding and prevention of wheeze may be assisted by directing attention to maternal smoking, breastfeeding and respiratory infections in infancy, atopy in childhood, rhino conjunctivitis in adolescence, and smoking and perhaps obesity in adult life.

\section{S113 THE EFFECT OF SMALL AIRWAYS DISEASE AND EMPHYSEMA ON THE ASSOCIATION BETWEEN SMOKING AND LUNG FUNCTION, AND BRONCHODILATOR RESPONSE}

doi:10.1136/thx.2010.150946.14

${ }^{1} \mathrm{~B}$ D Patel, ${ }^{2} \mathrm{H} O$ Coxson, ${ }^{3} \mathrm{P}$ G Camp, ${ }^{4} \mathrm{~S}$ G Pillai, ${ }^{5} \mathrm{~A}$ G Agusti, ${ }^{6} \mathrm{P} \mathrm{M}$ Calverley, ${ }^{7} \mathrm{C}$ F Donner, ${ }^{8} \mathrm{~B}$ J Make, ${ }^{2} \mathrm{~N}$ L Müller, ${ }^{9} \mathrm{~S}$ I Rennard, ${ }^{10} \mathrm{~J}$ Vestbo, ${ }^{11} \mathrm{E}$ F Wouters, ${ }^{4} \mathrm{~W}$ H Anderson, ${ }^{3} \mathrm{P} D$ Paré, ${ }^{3} \mathrm{R} D$ Levy, ${ }^{12} \mathrm{E}$ K Silverman, ${ }^{13} \mathrm{D}$ A Lomas. ${ }^{1}$ Department of Respiratory Medicine, Royal Devon and Exeter Hospital, Exeter, UK; '2Department of Radiology, University of British Columbia, Vancover, Canada; ${ }^{3}$ Division of Respiratory Medicine, University of British Columbia, Vancouver, Canada; ${ }^{4}$ GlaxoSmithKline, Raleigh, USA; ${ }^{5}$ Thorax Institute, Hospital Clinic Barcelona, Mallorca, Spain; ${ }^{6}$ University of Liverpool, Liverpool, UK; ' Division of Pulmonary Disease, S. Maugeri Foundation, Veruno, Italy; ${ }^{8}$ National Jewish Medical and Research Centre, Denver, USA; ${ }^{9}$ University of Nebraska, Omaha, USA; ${ }^{10}$ North West Lung Centre, Wythenshawe Hospital, Manchester, UK; ${ }^{11}$ Department of Respiratory Medicine, University Hospital Maastricht, Maastricht, Netherlands; ${ }^{12}$ Brigham and Women's Hospital and Harvard Medical School, Boston, USA; ${ }^{13}$ Department of Medicine, University of Cambridge, Cambridge, UK

Introduction and objectives The airflow limitation of COPD results from small airway disease and emphysema. These phenotypes are likely to have independent genetic risk factors. It is not known if the heterogeneity of COPD accounts for the relatively weak association between pack-years smoked and forced expiratory volume in $1 \mathrm{~s}$ $\left(\mathrm{FEV}_{1}\right)$ seen within smoking populations, or bronchodilator response (BDR). This study aimed to assess the effect of these phenotypes on the association between smoking and $\mathrm{FEV}_{1}$ and on BDR.

Method The international COPD genetics network is a multi-centre study aimed at identifying genes that predispose to COPD, in which high resolution computed tomography (HRCT) was used to quantify components of the COPD phenotype: (i) emphysema detected by radiologists (RE), (ii) emphysema assessed as per cent lowattenuation area (\%LAA) and (iii) airway wall thickness (AWT) for airways with an internal perimeter of $10 \mathrm{~mm}$ (Pi10), $20 \mathrm{~mm}$ (Pi20), and average per cent wall area (WA\%). They were then assessed for their effect on the association between smoking and lung function $\left(\mathrm{FEV}_{1} \%\right.$ predicted $\left.\left(\mathrm{FEV}_{1} \%\right)\right)$, and on $\mathrm{BDR}$.

Results RE data were available for 1159 individuals, 745 had complete data for Pi10, Pi20, AWT\% and \%LAA. The association between packyears smoked and $\mathrm{FEV}_{1} \%$ was greater in those without $(\mathrm{r}=-0.41)$, compared to those with, RE $(\mathrm{r}=-0.12, \mathrm{p}<0.001$ for difference in effect). AWT and RE correlated with $\mathrm{FEV}_{1} \%$ but had different relationships with smoking; AWT was positively associated with packyears but there was no relationship between RE severity and pack-years smoked. RE, \%LAA and AWT made independent contributions to $\mathrm{FEV}_{1} \%$. Post-bronchodilator increase in $\mathrm{FEV}_{1}$ was inversely associated with severity of RE (Abstract S113 Table 1), even after adjustment for pre-bronchodilator $\mathrm{FEV}_{1}(\mathrm{p}<0.01)$. BDR was also inversely associated with \%LAA ( $p=0.02$, and $p \leq 0.05$ adjusted for baseline $\mathrm{FEV}_{1}$ ).

\section{Abstract S113 Table 1}

\begin{tabular}{lllll}
\hline Severity of RE & Mild (5-25\%) & Moderate (25-50\%) & Severe (>50\%) & p (trend) \\
\hline Number & 228 & 185 & 266 & - \\
BDR, FEV1 (mls) & $171.3 \pm 188.2$ & $134.4 \pm 174.7$ & $100.2 \pm 129.6$ & $\leq 0.0001$ \\
\hline
\end{tabular}

Conclusion The AWT component of COPD, but not the severity of $\mathrm{RE}$, increases with pack-years smoked, and the association between pack-years and FEV1\% is greatest in those with an airway predominant phenotype. This suggests different gene-smoking interactions between phenotypes. RE and \%LAA independently contribute to FEV1\% and therefore measure different components of emphysema, however both were inversely associated with BDR.

\section{Measurements in patients with chronic cough S114 A DOUBLE BLIND, PLACEBO CONTROLLED, RANDOMISED, STUDY TO ASSESS THE EFFECTS OF PLACEBO, CODEINE AND TALNETANT, ON CITRIC ACID COUGH THRESHOLD IN HEALTHY SUBJECTS}

doi:10.1136/thx.2010.150946.15

S Khalid, A Woodcock, B Haumann, P Ventresca, S J Langley, J A Smith. University Hospital of South Manchester, Manchester, UK

Background Previous studies have shown a reduction in cough response to inhaled citric acid after blocking NK1, NK2 and also NK3 receptors in guinea pigs. NK3 receptor may be more relevant to study the role of tachykinins in cough due to their greater specificity for its agonist neurokinin B. We studied a specific NK3 receptor antagonist Talnetant to determine the effect on the human cough reflex sensitivity to citric acid in healthy individuals. Oral codeine and placebo were included as comparators.

Methods Double-blind, randomised, placebo-controlled, 4-period cross-over study in non-smoking healthy adult volunteers. A total of 28 subjects $(12 \mathrm{M}, 16 \mathrm{~F})$ with mean age of 33 years (SD 10.5, range 22-55) were studied. Each subject received A. matched placebos; B. Talnetant $200 \mathrm{mg}$; C. Talnetant $25 \mathrm{mg}$; D. Codeine $60 \mathrm{mg}$, in a double blind double dummy manner. Subjects were randomly assigned to one of four treatment sequences (ABCD, BCDA, DCAB, BDCA). Each study period was $24 \mathrm{~h}$ with citric-acid challenges performed at 2, 6, 10 and $24 \mathrm{~h}$ post dose and a 7 day washout period between treatments. Results There was no significant difference in logC5 Citric acid between Talnetant $25 \mathrm{mgs}, 200 \mathrm{mgs}$ and placebo at any time point (see Abstract S114 Figure 1). The 'positive' control codeine had a non-significant trend for improvement in $\log \mathrm{C} 5$ compared to placebo (all confidence intervals contained unity). Talantent was adequately absorbed with sustained blood levels at time points designed to coincide with the cough challenges.

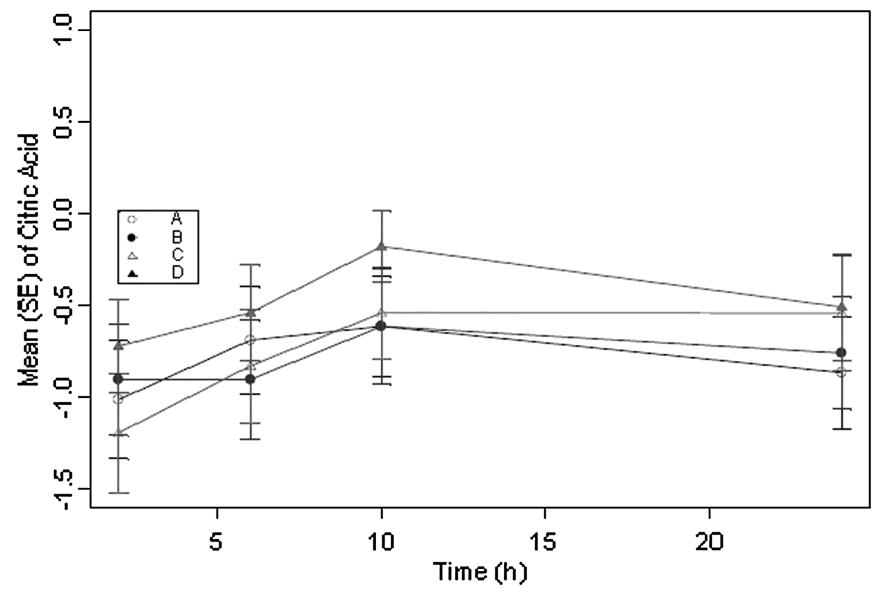

Abstract S114 Figure 1 
Conclusions In healthy volunteers, Talnetant had no significant effect on cough reflex sensitivity to citric acid despite an adequately powered study and sufficient systemic drug exposure. Possible explanations for this lack of efficacy are (1) NK3 receptors do not play an appreciable role in the healthy human cough reflex or (2) the role of NK3 receptors may be limited to the central nervous system where Talnetant has limited penetrance and receptor occupancy. Whilst this study suggests predominantly peripherally acting NK3 receptor antagonists do not influence the cough reflex in healthy volunteers, a significant effect in patients with a hypersensitive cough reflex cannot be excluded and this class of drugs may yet prove to have anti-tussive properties, especially with improved central activity.

\section{S115 MAGNITUDE OF COUGH RESPONSE TO INHALED CAPSAICIN DIFFERENTIATES BETWEEN HEALTH AND DISEASE}

doi:10.1136/thx.2010.150946.16

${ }^{1} \mathrm{E} C$ Young, ${ }^{1} \mathrm{H}$ Sumner, ${ }^{2} \mathrm{~A}$ Kelsall, ${ }^{1} \mathrm{~A}$ A Woodcock, ${ }^{1} \mathrm{~J}$ A Smith. ${ }^{1}$ University of Manchester, Manchester, UK; ${ }^{2}$ University Hospitals South Manchester NHS Foundation Trust, Manchester, UK

Background Patients with chronic cough (CC) have substantially higher 24-h cough rates compared to patients with asthma (A) or healthy controls (HC). CC patients also have a more sensitive cough reflex, when measured as the 'threshold' dose of a tussive agent (eg, capsaicin) inducing at least two or five coughs (C2/C5), although there is substantial overlap between CC and HC. We aimed to investigate if the 'magnitude' of cough response to inhaled capsaicin would better differentiate CC patients from A and HC subjects.

Methods We devised a cough challenge technique, with increasing doubling concentrations of capsaicin $(0.48-1000 \mu \mathrm{Mol})$ extended beyond the C5 threshold, up to the maximum tolerated dose. At each capsaicin concentration four single-breath inhalations were administered from a dosimeter $30 \mathrm{~s}$ apart. After each inhalation, the number of coughs in the first $15 \mathrm{~s}$ was counted. Using Generalised Estimating Equations (GEE), we explored the effect of group and gender on average cough response to increasing concentrations of capsaicin.

Results We studied 20 treatment resistant CC, 18 stable mild/ moderate $\mathrm{A}$ and $20 \mathrm{HC}$ subjects, matched for age and gender; (M:F $10: 10,9: 9,10: 10$, respectively), age $[$ mean $( \pm S D) 57.1$ years $( \pm 15.7)$,

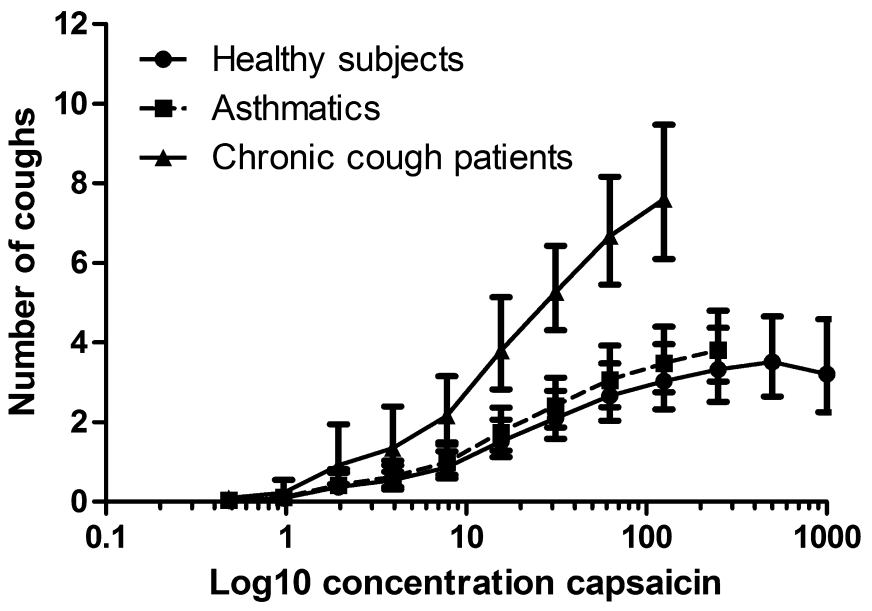

Abstract S115 Figure 1 Average cough frequency with increasing doubling doses of capsaicin (log 10 scale) according to group. Adjusted means and $95 \% \mathrm{Cl}$ from GEE model shown.
51.7 years $( \pm 13.5), 58.8$ years $( \pm 13.5) ; \mathrm{p}=0.17]$, and lung function [3.02L $( \pm 0.98), 2.96 \mathrm{~L}( \pm 1.10), 3.20 \mathrm{~L}( \pm 0.99) ; \mathrm{p}=0.72$ ]. CC (vs HC $\mathrm{p}<0.001$ ) and females (vs males, $\mathrm{p}<0.001$ ) cough significantly more after capsaicin (see Abstract S115 Figure 1). There was no significant difference between $\mathrm{A}$ and $\mathrm{HC}(\mathrm{p}=0.407)$.

Conclusions Magnitude of cough responses to inhaled capsaicin, beyond the standard endpoints:

- clearly discriminates chronic cough from healthy controls,

- demonstrates gender differences,

- may be valuable for investigation of physiological mechanisms and anti-tussive agents.

In addition to a reduced cough threshold, these findings are consistent with a failure of inhibitory mechanisms to prevent coughing to repetitive and potent stimuli in chronic cough.

\section{S116 URGE-TO-COUGH INTENSITY IN CHRONIC COUGH PATIENTS COMPARED TO ASTHMATICS AND HEALTHY CONTROLS}

doi:10.1136/thx.2010.150946.17

${ }^{1} \mathrm{E}$ C Young, ${ }^{1} \mathrm{H}$ Sumner, ${ }^{2} \mathrm{~A}$ Kelsall, ${ }^{1} \mathrm{~A}$ A Woodcock, ${ }^{1} \mathrm{~J}$ A Smith. ${ }^{1}$ University of Manchester, Manchester, UK; ${ }^{2}$ University Hospitals South Manchester NHS Foundation Trust, Manchester, UK

Background Healthy subjects inhaling increasing doses of capsaicin perceive an urge-to-cough (UTC) prior to initiating coughing. We compared subjective ratings of UTC intensity following inhalation of capsaicin in patients with chronic cough (CC), asthma (A) and healthy controls (HC).

Methods A double-blind, randomised block design, capsaicin cough challenge was performed using single-breath inhalations, separated by $1 \mathrm{~min}$, through a dosimeter (inspiratory flow rate limited). Seven individually pre-determined doses $(0.48-1000 \mu \mathrm{Mol}$; maximum dose inducing an average of at least five coughs) and one placebo dose were administered four times each, in four individually randomised blocks (Davenport et al), to reduce the bias associated with subjective UTC ratings. After each inhalation, UTC was rated on a modified Borg scale (0-10) and number of coughs in the first $15 \mathrm{~s}$ was recorded. Using Generalised Estimating Equations (GEE), we explored the effect of group and gender on average UTC intensity and average cough responses to increasing concentrations of capsaicin.

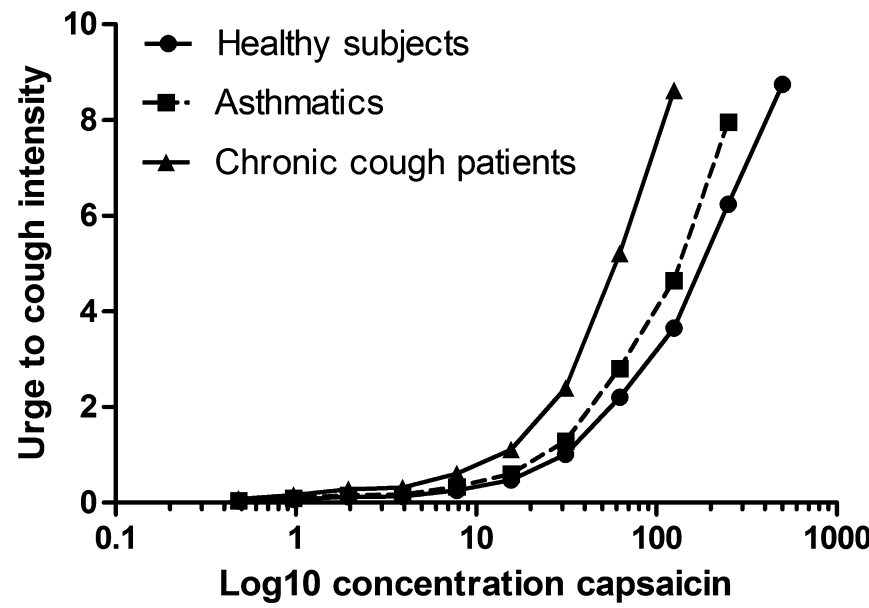

Abstract S116 Figure 1 Average urge to cough frequency with increasing doubling doses of capsaicin (log 10 scale) according to group. Adjusted means extracted from GEE model shown. 